\title{
SILENCIO, LENGUAJE Y NARRATIVA: INFLEXIONES Y ETNOGRAFÍAS DESDE LAS ANTROPOLOGÍAS DE LA VIOLENCIA ${ }^{1}$
}

JOSE A. CASTRO ${ }^{2}$

Desde el momento en que surgen las antropologías de la violencia, como una perspectiva que nos permite comprender y traducir experiencias de fractura y discontinuidad, son varias cosas las que suceden de manera simultánea. Una de ellas, consiste en una inflexión en la mirada, a la vez teórica y metodológica, que nos lleva a pensar la violencia a través de otras unidades de análisis y otros instrumentos de percepción, que hacen parte de un momento de reinvención al interior de la disciplina y también por fuera de ella.

La reinvención teórica que surge hace cerca de veinte años, está caracterizada por una inflexión en la mirada o un cambio de escala que se da de dos maneras específicas. La primera de ellas, a través de la necesidad de pensar las violencias en plural (Feixa y Ferrándiz, 2002),

\footnotetext{
${ }^{1}$ Algunas de las ideas reunidas en este escrito son extensión de un texto en preparación titulado "de la experiencia a la genealogía: cuatro inflexiones para una antropología de la violencia".

${ }^{2}$ Sociólogo de la Universidad de Caldas y Magíster en Antropología con énfasis en Antropología Social de la Universidad de los Andes. Ha sido investigador visitante en la Universidad Autónoma de Barcelona y profesor en varias universidades, particularmente en el Departamento de Lenguajes y Estudios Socioculturales de la Universidad de los Andes y en el Departamento de Antropología y Sociología de la Universidad de Caldas, donde orienta los seminarios sobre Postestructuralismo y Políticas de las Diferencias. Actualmente es coordinador del Centro de Estudios sobre Lenguaje y Alteridad e integrante del Grupo de Investigación Comunicación, Cultura y Sociedad de la Universidad de Caldas, donde coordina la línea de investigación sobre Antropologías de la Violencia. Igualmente, hace parte del Comité Interdisciplinario de Estudios Sobre la Violencia, la Subjetividad y la Cultura de la Universidad de los Andes, donde obtuvo diferentes becas de la Facultad de Ciencias Sociales mientras realizaba sus estudios de Postgrado. jose.castro@ucaldas.edu.co (1) ORCID: 0000-0002-8764-812X
} 
donde la mirada del investigador no debe centrarse en un solo tipo de violencia, ya sea simbólica, estructural, política o cotidiana, sino en las múltiples intersecciones que surgen entre ellas. Y la segunda, a través de una redefinición de la antropología, en la que su mirada especifica está centrada en la forma en que la violencia fractura el universo de significados que las personas construyen a través del encuentro con los otros. Esta inflexión teórica permitió que categorías como las de espacio, cuerpo, lenguaje, significación, subjetividad y vida cotidiana estuvieran en el centro del debate.

Por su parte, la reinvención metodológica, consistió en un "retorno al mundo de la vida cotidiana" (Castillejo, 2012), con el que, además de una reinvención teórica, la antropología debía centrarse en las múltiples maneras en que la violencia fragmenta el universo de significados que las personas construyen en diversos contextos. De esta forma, al detenerse por un momento en este tipo de experiencias, se resignificaron las metodologías centrales de la disciplina, como lo son la traducción, la enunciación y el trabajo de campo, posibilitando, a través de este cambio de escala (que implicaba múltiples experiencias, niveles y dimensiones), el registro de las experiencias cotidianas causadas por la violencia sin dejar por fuera las estructurales.

Este giro posibilitó, de manera simultánea, redefinir la manera en que los antropólogos realizaban etnografía en contextos de violencia y, al mismo tiempo, traducir de otra manera este tipo de experiencias. Esto explica, por ejemplo, que durante los últimos años los antropólogos hayan estado en una gran cantidad de escenarios como comisiones de la verdad, versiones libres, zonas de guerra y postguerra, campos de refugiados, comunidades de desplazados, etc., donde su mirada se centraba en la manera en que las personas experimentaban la violencia y reconstruían su vida en medio de la guerra o en situaciones posteriores a ella.

Esta inflexión, a la vez teórica y metodológica, es la que define la particularidad de la mirada antropológica sobre la violencia. "Se trata, pues, de estudiar la violencia no tanto como un acto sino como un continuo (Scheper-Hughes y Bourgois, 2004: 1-5), no tanto como excepción sino como normalidad, no tanto como política sino como cotidianidad, no tanto como estructura, sino como símbolo, no tanto como amenaza de guerra sino como negociación de paz" (Feixa \& Ferrándiz, 2004, p. 160). De esta forma, surgen diferentes categorías que se han convertido en conceptos esenciales para pensar la violencia de esta manera, como la de acontecimiento (Mélich y Bárcena, 2000), la de anatomopolítica y biopolítica (Foucault, 2007) y la de subjetividad. 
Cada una de ellas nos recuerda que los conceptos de experiencia y de acontecimiento ${ }^{3}$ (Castro, 2014) son centrales para la mirada particular que articula la antropología. Ambas categorías han sido para mí definitivas, pues ante la multiplicidad de definiciones que existen sobre la violencia, al pensarla como experiencia o como acontecimiento, esto nos permite involucrar de manera simultánea, categorías y experiencias que son centrales en la antropología de la violencia (Y también en la Metamorfosis de Kafka): la identidad, el cuerpo, el lenguaje, el perdón, el acogimiento.

En el momento actual asistimos a un despliegue de imágenes, conceptos y discursos en los cuales la reconstrucción del pasado (que es narrativa y no ontológica) se hace cada vez más difusa. Los términos de referencia, así como los instrumentos de percepción que se utilizan, son cada vez más arriesgados, en el mal sentido de la palabra. La multiplicidad de informes, documentos e instituciones relacionados con la memoria nos deben llevar también a un momento de detenimiento, para repensar la forma en que nos acercamos a cada uno de estos temas. Tengo la impresión de que hemos pasado de un momento en que se insistía en "darle la voz al otro" a uno de aturdimiento, donde no hay detenimiento ni tiempo para escuchar.

Así, las imágenes que circulan, los textos y los informes se van convirtiendo, poco a poco, en reconstrucciones sin significado y $\sin$ interpelación, donde la imaginación del futuro es igual de difusa que la reconstrucción del pasado. Tal vez por esta razón, es importante recordar que cada imagen es experiencia capturada (Sontag, 2008), que la identidad es narrativa y polisémica (Mélich, 2001), que la subjetividad aparece configurada en los textos (Barthes, 1997), que la memoria es tensión inacabada entre recuerdo y olvido (Jelin, 2002) y que el silencio tiene una textura y una gramática particular.

Este es para mí el sentido de regresar a un tema como las antropologías de la violencia, al cual he podido acercarme de manera vital y académica desde hace ya varios años (Castro, 2012). El número que hoy presenta la Revista de Antropología y Sociología Virajes surge en un momento particular, ya que tal vez la "luminosidad puede ser una trampa...", pero al tiempo, investigadores de diferentes lugares le apuestan a construir una mirada sobre el tema, reinventando sus límites y actualizando sus fronteras, en medio del desplazamiento, el miedo, la agresión, la amenaza y el exilio.

\footnotetext{
${ }^{3}$ Ambas categorías son retomadas de cuatro autores que las construyen en dos textos distintos. Por una parte se encuentran Skliar y Larrosa (2011) quienes al hablar de "Experiencia y Alteridad en Educación", definen la experiencia no como "eso que pasa", sino como "eso que me pasa"; y, por la otra, se encuentran Barcena y Melich (2000), quienes al referirse a Auschwitz y la experiencia concetracionaria, definen el acontecimiento como aquello que después de suceder hace que nada vuelva a ser como antes. los cuatro autores vienen del campo de la filosofía de la educación y construyen ambas ideas tomando como punto de referencia La Metamorfosis de Kafka.
} 
Por esta razón, las antropologías de la violencia son un campo abierto, una mirada que se desplaza y una reinvención en una disciplina que es inacabada, pues más allá de una inflexión teórica o metodológica, se sustenta en nuestras múltiples metamorfosis, en el riesgo, en las diferentes maneras de interpelar el poder y en la genealogía que antecede a cada investigador que se acerca a cada uno de estos temas, con la intención de traducir la experiencia del otro, y en muchos casos también, la experiencia propia.

\section{Bibliografía:}

Barthes, R. (1997). Introducción al análisis estructural de los relatos. Buenos Aires: Centro Editor de América Latina.

Castillejo, A. (2012). Guerra, cotidianidad y órdenes globales: notas antropológicas para una relectura de la violencia en Colombia. Bogotá: Inédito.

Castro, J. (2012). “El fracaso de lo imaginado: gramáticas y texturas del pasado de las víctimas de la UP". En: Castellanos, J., Correa, A., Gálvez. A y Torres, W. "Para Vencer el Miedo: Respuestas a los Impactos de la Guerra en el Centro y Sur de Colombia Entre 1980 y 2010". Tolima: Sello Editorial U.T.

Castro, J. (2014). El Desplazamiento Forzado en Colombia: Experiencia y Categoría. Notas al Margen Para Una Antropología de lo Efímero. Manizales: Inédito

Feixa, C; Ferrándiz, F. (2004). Una mirada antropológica sobre las violencias. Alteridades, enero - julio, Volumen 14, Número 27, Distrito Federal, México: Universidad Autónoma Metropolitana.

Foucault, M. (2007). Nacimiento de la biopolítica. Buenos Aires: Fondo de Cultura Económica. MÉLich, J. C; Bárcena, F. (2000). La educación como acontecimiento ético. Barcelona: Paidós

Mèlich, J C. (2001). La ausencia del testimonio: ética y pedagogía en los relatos del Holocausto. Barcelona: Antrophos.

Mèlich, J.C., (2010). Etica de la compasión. Barcelona: Gedisa.

Skliar, C.; Larrosa, J. (2011). Experiencia y alteridad en educación. Rosario: Homo Sapiens/ FLACSO.

Sontag, S. (2007). Sobre la fotografía, Barcelona: Debolsillo. 